\title{
Correspondence
}

\section{Expressed Emotion and Relapse in Schizophrenia}

With reference to the correspondence under this heading (Journal, June 1986, 148, 741-742) neither Dr Leff nor Dr Vaughn was involved in any stage of the assessment and editing of the paper between receipt of the manuscript and publication.

Editor

Deficits of Chronic Schizophrenia in Relation to Longterm Hospitalisation

Sir: Mathai \& Gobinath's study (Journal, May 1986, $148,509-516)$ casts further doubt on the role of 'institutionalisation' in determining the course of chronic schizophrenia. We have argued (Abrahamson \& Brenner, 1978; Abrahamson, 1983) that the positive correlation between length of stay and negative handicaps characteristic of previous studies was a reflection of the inadequacy of a cross-sectional approach. A cohort of patients with negative handicaps which persisted largely unchanged through hospital courses of 30 years or more was mainly responsible for the positive correlations we obtained retrospectively, which were strikingly similar in pattern to those obtained by Wing \& Brown (1975).

It seems possible that Mathai $\&$ Gobinath have avoided this particular pit-fall because few such patients now exist in their long-stay populations or, more probably, because they were screened out by the diagnostic and exclusion criteria. It is notable that none of the patients were aged over 55 years and that only $8.8 \%$ of the NIMHANS and $18 \%$ of the $\mathrm{MH}$ long-stay populations were included. Whilst avoiding one source of bias others may have been introduced by the exclusion process, or submerged in the cross-sectional analyses. We found it revealing to relate the scores on disability scales to length of stay year-by-year rather than to longer time spans. In addition, despite their limitations, case-note studies provided an invaluable longitudinal dimension, the importance of which is underlined by prospective studies of long-term courses (Bleuler, 1978; Harding \& Strauss, 1985). The numbers in Mathai \& Gobinath's groups are sufficiently small for detailed case-note studies to be feasible for all the patients included and samples of those excluded.

The main impression from the Goodmayes study, which has been reinforced by continuing experience with some of the patients concerned, is of the individual consistency of courses. A longitudinal framework is therefore essential to do justice to social influences, which appear to operate within narrow, perhaps biologically determined, constraints over a very long time course. A much more complex explanation than either a disease process or a social model alone provides is likely to be required for the re-evaluation of 'institutionalisation'.

\section{DAVID ABRAHAMSON}

Goodmayes Hospital,

Barley Lane,

Ilford, Essex IG3 $8 X J$

\section{References}

Abrahamson, D. \& Brenner, D. (1978) A Siudy of the Old Long. stay' Patients in Goodmayes Hospital. Report to DHSS. London: DHSS.

- (1983) Schizophrenic deterioration: A discussion. British Journal of Psychiatry 143, 82-83.

BLEULER, M. (1978) The Schizophrenic Disorders: Long-term Patient and Family Studies. London: Yale University Press.

Harding, C. M. \& Strauss, J. S. (1985) The course of schizophrenia: An evolving concept. In Controversies in Schizophrenia (ed. $M$. Alpert) London: Guildford Press.

WiNG, J. K. \& BRoWN, G. W. (1970) Institutionalism and Schizophrenia. Cambridge: Cambridge University Press.

\section{The Northwick Park Study of First Episodes of Schizophrenia}

Sir: Hidden away in the four papers on first episodes of schizophrenia from Northwick Park (Journal, February 1986, 148, 115-143) is information of interest to psychogeriatricians. First, the inclusion of patients "aged between 15 and 70 years, with a first psychotic illness, not unequivocally affective", would suggest that British psychiatrists accept that schizophrenia can develop for the first time in patients over the age of 40 or 45 . Second, Table I (page 116) shows that three patients were excluded as being outside the age range. Were any of these over the age of 70 ? Third, Table I (page 129) shows that 37 of $253(14.6 \%)$ patients were aged 40 or over on admission. The Table shows the expected excess of males over females for all ages, but does this relationship hold for the older age groups? Fourth, Table I 